\title{
The Research of Status's Influence on Consumers' Self-Brand Connection with Luxury Brands: Moderating Role of Self-Esteem and Vanity*
}

\author{
Sheng-Hong Ye, Xiao-Ting Liu, Sheng-Yu Shi \\ Management School, Jinan University, Guangzhou, China \\ Email: 15121038199@163.com
}

Received 8 November 2014; revised 5 December 2014; accepted 20 December 2014

Copyright (C) 2015 by authors and Scientific Research Publishing Inc.

This work is licensed under the Creative Commons Attribution International License (CC BY).

http://creativecommons.org/licenses/by/4.0/

(c) (i) Open Access

\begin{abstract}
With the rapid development of social economy and the improvement of living quality, consumers are inclined to demonstrate their social status by using luxury brands today. This research explores the influence that the status of consumers makes on their self-brand connection with luxury brands, as well as the regulating effect of self-esteem and vanity from the perspective of Chinese cultural background. The analysis of the data shows that: in traditional Chinese cultural background, the higher the status of the consumer is, the higher the comsumer's self-brand connection with luxury brands is, and vice verse. Self-esteem and vanity have a regulating effect on this relationship. When consumers' self-esteem level is low, if their status is lower too, then their self-brand connection with luxury brands is higher than that of the high status; and when consumers' self-esteem level is high, the result is opposite. The level of consumers' social status has no significant effect on their selfbrand connection with luxury brands when they are in low vanity, while to highly peacockish consumers, the self-brand connection with luxury brands of those with low status is significantly lower than that of the high status. We also have discussed the results and given the marketing proposal in the end.
\end{abstract}

\section{Keywords}

Self-Brand Connection, Status, Self-Esteem, Vanity, Luxury Brands

\footnotetext{
"Ministry of National Education Fund Project” Self-brand Relationship Links under Chinese Cultural Background of: Research of Differential Pattern Based on the Perspective” (12YJC630269); Innovative Projects of Jinan University Enterprise Institute, “Consumers-brand Relationship under Chinese Cultural Background: Based on the Perspective of Social Circle” (2013CP006).
}

How to cite this paper: Ye, S.-H., Liu, X.-T. and Shi, S.-Y. (2015) The Research of Status's Influence on Consumers' Self-Brand Connection with Luxury Brands: Moderating Role of Self-Esteem and Vanity. Open Journal of Business and Management, 3, 11-19. http://dx.doi.org/10.4236/ojbm.2015.31002 


\section{Introduction}

Self-brand connections (SBC) means that consumers use certain brands to build, strengthen and express themselves [1]. The connection is set up when consumers borrow brand association to build themselves or to transfer the conception of "self" to others. Previous researches have shown that the self-brand connection is one of the important factors that influence consumers' brand evaluation of high and low [2]. It positively affects brand association, brand reputation and brand loyalty [3], and also has a positive effect on consumer purchase intention and brand attitude [4]. Therefore, self-brand connection is an important topic in the marketing industry which could guide the marketing practices.

In addition to the effects that self-brand connection has on the above factors, scholars at home and abroad have also discussed its front influence factors, and abundant research results have been achieved. Throughout these related researches, there are three common problems as following: first, they are mostly based on the perspective of "reference group" to discuss its factors, influence on the formation of SBC, such as its type and characteristics, but the research from other angles is very limited; second, most of them are under the background of western culture, using western theories to study Chinese market consumption phenomenon and consumer behavior, without a specific consideration of Chinese cultural scene and social values, so it's hard to avoid "unacclimatized" problems. Many scholars have found that, due to the differences between eastern and western cultural tradition and cultural background, many consumer behaviors which both occur in east and west show diametrically adverse conclusions, so it's not rigorous to explain such a phenomenon just through western consumption models; third, they are used to choosing general public brands as the research stimuli, and pay little attention to the SBC between consumers and those special brands, such as luxury brands, so there is huge research blank in this field, such as the characteristics, the influencing elements, and so on.

In fact, in recent years, with the sustained and rapid development of economy, Chinese people's living condition is constantly better, they have shown great consumption enthusiasm about luxury brands, the degree they connected with luxury brands is deepening overall. According to the report of global market for luxury goods from Bain POV, China has become the biggest luxury consumption market of the world, buying $29 \%$ of global luxury goods, total spending 116 billion yuan in 2013. The growing luxury consumption ability and preference of Chinese consumers has drawn great attention of the world's luxury companies, and so far, China has almost all of the world's top brands' stores.

This phenomenon also arouses scholars' intense interest. Most of the relevant studies connect the luxury consumption motivation of Chinese consumers with their social status, and declare that consumers' social status is negatively correlative with the SBC between themselves and luxury brands. Compared with those with higher social status, the ones with low social status have stronger requirements for luxury brands, so the SBC between themselves and luxury brands is higher, because they hope to show and improve their social status by using luxury brands. We can often see the consumers whose status is not high consume luxury brands in our daily life, too. But in China, the conception of status and class is rooted in people's mind. Under this kind of social norm, people's consumption behavior ought to follow the rule of "behavior should match status" [5]. Then how to explain the luxury consumption phenomenon of Chinese consumers? By induction and combing relevant literatures, we find two typical social values factors which may affect consumers' self-brand connection with luxury in the context of Chinese culture: self-esteem and vanity, thus we build the study model, and look forward to explaining the contradiction between the theory and reality.

To sum up, in order to make up the insufficiencies of existing researches on SBC, this thesis will explore how Chinese typical social values factors, status, self-esteem and vanity, would affect Chinese consumers' self-brand connection with luxury brands from the perspective of Chinese traditional values. The purpose is to enrich the outcomes of self-brand connection, to explain the luxury consumption characteristics of Chinese consumers and its influencing factors, to help luxury companies know Chinese consumers and Chinese market better, and to provide marketing revelations for their business development in China.

\section{Research Hypothesis and Model}

\subsection{The Influence of Status on SBC}

The general definition of status is the location of the individual in society [6]. Status is always connected to hierarchies, people with admissive high status in society usually have good fame and high authority [7]. Status can 
be identified and strengthened by consumption behavior. Consumption of luxuries is a way consumers use to show their status [8]. Chinese Confucian culture speaks highly of social harmony. It admits the objectively existing differences of status between people and asks people to understand the distinctions of different status and to play their roles, so as to achieve social harmony and stabilization [5]. The social rules of "behavior should match one's status" ask people to recognize their roles and status appropriately in a certain situation. Behavior and outward expression of individuals should keep pace with status. Under the influence of this Confucianism, people are inclined to achieve the harmony among human, society and environment by sticking to the relative consumption behavior which matches their status.

People with strong power tend to accept and obey the conventional social norms and cognition, while those with low power are inclined to adjust the cognitive according to the actual needs of themselves [9]. The word "power" in the research of Wang Xue et al. (2014) [9] actually refers to "authority". We have known that people with high status usually have high authority [7], so it's not difficult for us to draw a conclusion that strong power means high status, and vice versa. Then combining with the research findings of Wang Xue et al. (2014) [9] about "power", we can believe that the higher the individuals' status is, the more naturally they will think about purchasing luxury brands, because they believe that it's right to accept and obey the conventional social norms, and luxuries are tailored for people of higher status, such as themselves, so they will have a high degree of psychological and emotional approval with luxury brands, the SBC of them with luxury brands is stronger doubtlessly. Just as Sun Chunchen (2008) emphasizes that the consumption capacity of individuals is an important symbol and expression of social status, high position needs to be transferred by high consumption [10]. O'cass and McEwen (2004) also declare that purchasing luxuries is a consumption behavior that consumers occur to transfer and strengthen their status and image, or promote others to evaluate themselves in their expected way [11]. This discussion informs the following hypothesis:

H1: The status has a great positive effect on the SBC between luxury brands and consumers. The higher the status of consumers is, the higher the SBC is.

\subsection{The Regulating Effect of Self-Esteem}

Self-esteem is a positive or negative attitude that estimates the individual's holds about his ability, achievement, value and importance [12]. In a word, self-esteem is how he feels about and evaluates himself. The constitution of Branden's study shows that self-esteem can be divided into internal and external parts. The internal part refers to the opinions, believes, evaluations and cognitions about oneself which could influence the external part, one's behaviors.

According to the finding of Wang Xue et al. (2014), the views that consumers with high self-esteem hold of themselves is positive and affirmative, they do believe that they are welcome and don't care about the opinions of the others, so the consumption habits of them are jarless; but to those with low self-esteem, they hold negative views toward themselves and always experience negative emotions, such as anxiousness, fear, diffidence, and insecureness, so they'd like to adjust their behaviors according to the situations and the views of others [10]. Rudich and Gregg (2007) deem that people with low self-esteem lack self-confidence, their evaluations of themselves are low, they don't think that they are successful and are afraid of the disavowal from others, so they change their original consumption patterns in order to avoid being discriminated and excluded because of their not high enough status [13]. When the identity is under threat, the consumers with high self-esteem will not change product preferences, however, those with low self-esteem will avoid buying the products which could indicate their real identities [14]. Rucker et al. (2012) also find that low self-esteem sense will motivate the individual to develop high purchase willingness toward those merchandises which could symbolize high status [11]. Because of the high status symbolic meaning of luxury brands, we can make an inference that the SBC between luxury brands and consumers of low self-esteem will be higher. We get the following hypotheses from this discussion:

H2: The interaction effect of self-esteem and status has an effect on the SBC between luxury brands and consumers.

H2a: Among those people with low self-esteem, people with low status have stronger SBC with luxury brands than those with high status.

H2b: Among those people with high self-esteem, people with low status have weaker SBC with luxury brands than those with high status. 


\subsection{The Regulating Effect of Vanity}

Vanity is one kind of personality characteristic. There are not too many researches about the characteristic of vanity both at home and abroad. Zhang Weilong (2004) puts forward that vanity can be divided into two parts, appearance vanity and achievement vanity, appearance vanity is characterized by pursuing wealth and perfect self-image [15]. Yuan Shaofeng et al. (2009) think the essence of vanity is close to conspicuous consumption, people with vanity will put special emphasis on appearance [16]. Schiffman et al. (2011) also think that vanity is closely related to personal image and individuals' behavior is the externalization of vanity, the more intense the vanity of a consumer is, the more likely of them to occur or change consumption behaviors to perfect their selfimage [17]. So it's no difficult to find that perfect self-image is a crucial part of vanity. Self-image comes from products, and different products transmit different information of oneself to others [18], so vanity can be expressed and recognized through the products and brands consumers purchase.

Consumers expect to demonstrate self-image by consuming expensive luxury brands, so that they could gain the respect and recognition of others, and then they could own the ideal social status and identity. Just as the study of Du Jialing (2002) proves that people with vanity is more willing to use luxury brands to attract the attention of others. Therefore, we have reasons to believe that vanity will affect the SBC between consumers and luxury brands. The higher the vanity of consumers is, the more intense attention they will pay to their physical appearance and achievements, as a result, the willingness of them to enhance attractiveness and demonstrate their successful status by purchasing luxury brands is more intense, too. What's more, compared with consumers with high status, it's more necessary for consumers of low status to perfect self-image and get rid of the low status of them by consuming luxuries, so their SBC with luxury brands will be higher.

Thus, we can develop the following hypotheses:

H3: The interaction effect of vanity and status has an impact on consumer's SBC with luxury brands.

H3a: Among those people with high vanity, consumers with low status have stronger SBC with luxury brands than those with high status.

H3b: Among those people with low vanity, consumers with low status have weaker SBC with luxury brands than those with high status.

And now we can draw the theory model of the influence that status, self-esteem and vanity have on SBC, just as showing in Figure 1. The status is independent variable, and self-esteem and vanity are regulated variables.

\section{Research Design}

\subsection{Questionnaire Design}

In this study, the measurements are all maturity scales. The questionnaire is divided into three parts. The first part is the investigation about demographic characteristics of survey respondents and the status of consumers. The second one is the measurement about self-esteem and vanity characteristic of consumers. The last one is the SBC between consumers and provided luxury brands.

According to western researches, the most direct and obvious indicator to measure status is to ask people's income. Some scholars deem that individual's relative income equals to his social status [19]. Therefore, this thesis adopts income as criteria of classification of status. By calculating "the amount of monthly disposable", we finally partition five income levels to represent testee’s status: " 1 " means "1700 - 3300 yuan per month”, "2" means “3300 - 4700 yuan per month”, “3” means “4700 - 5700 yuan per month”, “4” means “5700 - 8400 yuan per month", and " 5 ” means "more than 8400 yuan per month".

The dependent variable, self-brand connection, is measured by seven questions of Escalas and Bettman [1]. The regulated variable, self-esteem, adopts five positive key questions of self-esteem scale of Rosenberg [20]. We use the vanity feature scale of Netemeyer et al. [21] to measure testee's vanity characteristic, which contains "appearance of concern" and "achievement care" two parts and 10 items in total. All scales we use are 7-point Likert Scales, in which "1" indicates strongly disagreement, while "7" represents extremely agreement.

As to the choice of luxury brands, ten consumers queuing to buy luxuries in Harbour City of Hong Kong are interviewed. The result shows that compared with watches, jewelry, cars and other products, cosmetics and bags of luxury have a higher purchase rate and are more popular. Considering that the users of cosmetics mostly are women, men don't know much about most of the cosmetics brands, so we choose luxury luggage brands as stimuli. According to the interview, four brands are finally selected: Louis Vuitton, Chanel, Gucci, and Prada. 


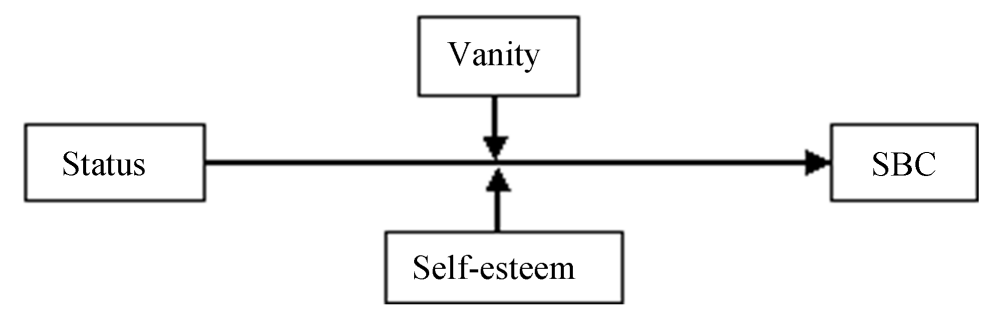

Figure 1. Conceptual model.

\subsection{Reliability and Validity of Questionnaire}

1) Reliability Analysis: The scales used in the study are mainly maturity scales developed by previous researchers, and the required data are obtained through questionnaires. After the statistical analysis, Cronbach's $\alpha$ coefficient of three variables, self-esteem, vanity features and SBC are $0.893,0.855,0.984$, reliability is all at a high level. It can be considered that the reliability of sample survey can be accepted.

2) The validity analysis: The scales used in the study are mainly maturity scales developed by previous researchers, and the required sample data are obtained through questionnaires, too. The results of statistical analysis show that the KMO values of three variables, self-esteem, vanity features and SBC are 0.865, 0.798, 0.929, reliability is all at a high level, too. So the validity of sample survey can also be accepted.

\subsection{Data Collection}

Questionnaires are distributed to the forum via the Internet. In order to ensure the quality of the questionnaire, we reward each user 5 forum points. A total of 220 were recovered. Excluding invalid questionnaires 18 copies, we received valid ones 202 copies, the efficiency of questionnaires is $91.8 \%$.

\section{Data Analysis}

\subsection{Statistical Analysis of Sample Description}

In the survey, male respondents account for $39.5 \%$, and female respondents account for $60.5 \%$. On the age structure, people younger than 22 years old account for $9.3 \%$, those who are between 22 and 32 years old account for $29 \%$, those from 32 to 42 years old account for $42 \%$, those from 42 to 52 years old account for $16 \%$, the ones from 52 to 67 years account for $3.1 \%$ and the others account for $0.6 \%$. On the status structure, consumers with lower status account for $37.1 \%$, and those of higher status account for $32.2 \%$. The number of higher status and lower status groups is nearly the same. The interviewers are usually from 22 to 52 years old, whose consuming capacity is the most strong in current market. The distributed architecture of samples is reasonable.

\subsection{Empirical Test of Hypothesis}

\subsubsection{The Influence of Status on SBC}

People with low and low-middle income are grouped into lower status in this thesis, middle-high and high income into higher status, and those with middle income are removed. Using one-way ANOVA statistical analysis to test the main effect of variables, we have tested the relationship of consumers, status and SBC with luxury brands.

The results are shown in Table 1 . The SBC between luxury brands and consumers with different status is significantly different $(\mathrm{F}=103.357, \mathrm{P}=0.000)$. The mean of the SBC between luxury brands and consumers with lower status is $(M=2.91, S D=1.482)$ smaller than that with higher status $(M=5.73, S D=1.800)$. So $H 1$ is verified. That's to say, the status indeed has a great positive effect on the SBC between luxury brands and consumers. The higher the status of consumers is, the higher their SBC with luxury brands is.

\subsubsection{The Regulated Effect of Self-Esteem}

We use the statistical method of multivariate analysis of variance to test the interaction of self-esteem with SBC and the status. According to sample self-esteem scores of arithmetic average of each sample item based on the 
Table 1. One-way ANOVA.

\begin{tabular}{cccccc}
\hline Dependent V: SBC & Quadratic Sum & Df & Mean Square & F & Significance \\
\hline Interblock & 277.187 & 1 & 277.187 & 103.357 & 0.000 \\
Interclass & 370.093 & 138 & 2.682 & & \\
Sum & 647.280 & 139 & & & \\
\hline
\end{tabular}

questionnaire, we find that the average 5.5 is the demarcation point. It belongs to the high self-esteem group if the score is higher than 5.5 points, and to the low self-esteem group if not.

The results of homogeneity of variance test show that there are significant differences $(\mathrm{F}=1.399, \mathrm{P}=0.226>$ 0.05 ) among the variance of every group. Because of the homogeneity of variance, the test of the interaction effects can be achieved. The test results are shown in Table 2. According to the table, self-esteem has a significant influence on SBC $(\mathrm{F}=17.412, \mathrm{P}=0.000<0.05)$; the interaction between social status and self-esteem also affects SBC significantly ( $\mathrm{F}=8.549, \mathrm{P}=0.004<0.05$ ), $\mathrm{H} 2$ is verified. The SBC means of the four groups are shown in Table 3. For a more intuitive analysis, the data in Table 3 has been plotted in Figure 2. From the figure, among those people with low self-esteem, people with low status have stronger SBC with luxury brands (M $=4.833)$ than those with high status $(M=4.102)$. Significant differences between the means of the two groups verify H2a. Among those people with high self-esteem, people with low status have weaker SBC with luxury (M $=3.066)$ than those with high status $(M=5.179)$. The significant differences verify H2b.

\subsubsection{The Regulated Effect of Vanity}

We use multivariate analysis of variance to analyze the interaction of vanity feature, status and SBC. According to the scores of vanity of arithmetic average based on each questionnaire item, we calculated mean 5.2 as the demarcation point. If the score is higher than 5.2, it belongs to high vanity group, and it belongs to low vanity group if the score is lower than 5.2.

The results of homogeneity of variance test show that there are significant differences $(\mathrm{F}=0.553, \mathrm{P}=0.697>$ 0.05) among the variance of every group. Because of the homogeneity of variance, the test of the interaction effects can be achieved. Here we use SPSS software to test the interaction effects of vanity feature and status on SBC. The results are shown in Table 4. According to Table 4, vanity has a significant influence on SBC (F = $77.404, \mathrm{P}=0.000<0.05)$; interaction between social status and vanity feature also affects SBC a lot $(\mathrm{F}=17.951$, $\mathrm{P}=0.0040<0.05$ ), thus $\mathrm{H} 3$ is verified. The SBC means of the four groups are shown in Table 5 . The data in Table 5 has been plotted in Figure 3 in order to analyze more intuitively. From the figure, among those people with low vanity, people with low status have weaker SBC with luxury brands $(\mathrm{M}=2.37)$ than those with high status ( $\mathrm{M}=2.814)$, so H3a is rejected. Among those people with high vanity, people with low status have quite weaker SBC with luxury brands $(M=3.579)$ than those with high status $(M=6.279)$. The significant differences verify H3b.

\section{Conclusions and General Discussion}

We have discussed the influence that the status of consumers makes on their self-brand connection with luxury brands, as well as the regulating effect of self-esteem and vanity from the perspective of Chinese cultural background. The analysis of the data shows that:

1) The status has a great positive effect on the SBC between luxury brands and consumers. The higher the status of consumers is, the higher their SBC with luxury brands is, and vice verse. That's to say, the luxury consumption behavior of Chinese people follows the traditional social norm of "behavior should match status". Chinese consumers with lower status are more rational than western consumers.

2) Self-esteem has a significantly positive regulating effect on above-mentioned relationship. When consumers' self-esteem level is low, if their status is low too, their self-brand connection with luxury brands is higher than that of the high status; and when consumers' self-esteem level is high, the result is opposite. This is in agreement with most scholars' research conclusions.

The evaluations that consumers with lower self-esteem hold of themselves is diffident and negative, they feel insecure about their social status, and it's a very important way for them to obtain self-affirmation from oth- 
Table 2. Analysis of regulatory effect of self-esteem.

\begin{tabular}{ccccccc}
\hline & \multicolumn{2}{c}{ Dependent Variable: SBC } & & & \\
\hline Source & III Quadratic Sum & Df & Mean Square & F & Sig. \\
\hline Calibration model & $150.566 \mathrm{a}$ & 3 & 109.012 & 46.295 & 0.000 \\
Intercept & 1769.653 & 1 & 1769.653 & 751.529 & 0.000 \\
Status & 140.000 & 1 & 140.000 & 59.455 & 0.000 \\
Self-esteem & 41.000 & 1 & 41.000 & 17.412 & 0.000 \\
Status $\times$ Self-esteem & 20.131 & 1 & 20.131 & 8.549 & 0.004 \\
\hline
\end{tabular}

a. $\mathrm{R}=0.505$ (modulation $\mathrm{R}=0.494$ ).

Table 3. Mean of each group.

\begin{tabular}{ccc}
\hline Status & Self-esteem & Mean \\
\hline Low & Low & 4.833 \\
& High & 3.066 \\
\hline High & Low & 4.102 \\
& High & 5.179 \\
\hline
\end{tabular}

Table 4. Mean of each group.

\begin{tabular}{cccccc}
\hline & \multicolumn{2}{c}{ Dependent Variable: SBC } & & & \\
\hline Source & III Quadratic Sum & Df & Mean Square & F & Sig. \\
\hline Calibration model & $492.201 \mathrm{a}$ & 3 & 164.067 & 95.317 & 0.000 \\
Intercept & 1373.651 & 1 & 1373.651 & 789.039 & 0.000 \\
Status & 59.964 & 1 & 59.964 & 34.837 & 0.000 \\
Vanity feature & 132.607 & 1 & 132.607 & 77.040 & 0.000 \\
Status $\times$ Vanity feature & 30.899 & 1 & 30.899 & 17.951 & 0.000 \\
\hline
\end{tabular}

a. $\mathrm{R}=0.644$ (modulation $\mathrm{R}=0.637$ ).

Table 5. Mean of each group.

\begin{tabular}{ccc}
\hline Status & Vanity Feature & Mean \\
\hline Low & Low & 2.370 \\
& High & 3.579 \\
\hline High & Low & 2.814 \\
& High & 6.279 \\
\hline
\end{tabular}

ers, so they will show a strong interest and affection in luxury brands with swanky, and the lower the position is, the deeper their interest and affection in luxury brands are, thus the SBC is higher, too. But to those with higher self-esteem, their opinions about themselves are positive and affirmative, they have enough sense of security about their social status, they don't care about the opinions of others and there are no enough reasons for them to change consumption habits, therefore, they show little interest and enthusiasm for the behavior of strengthening their social position by using luxury brands, and the lower the status is, the less the interest and enthusiasm is, and the lower the SBC is. 

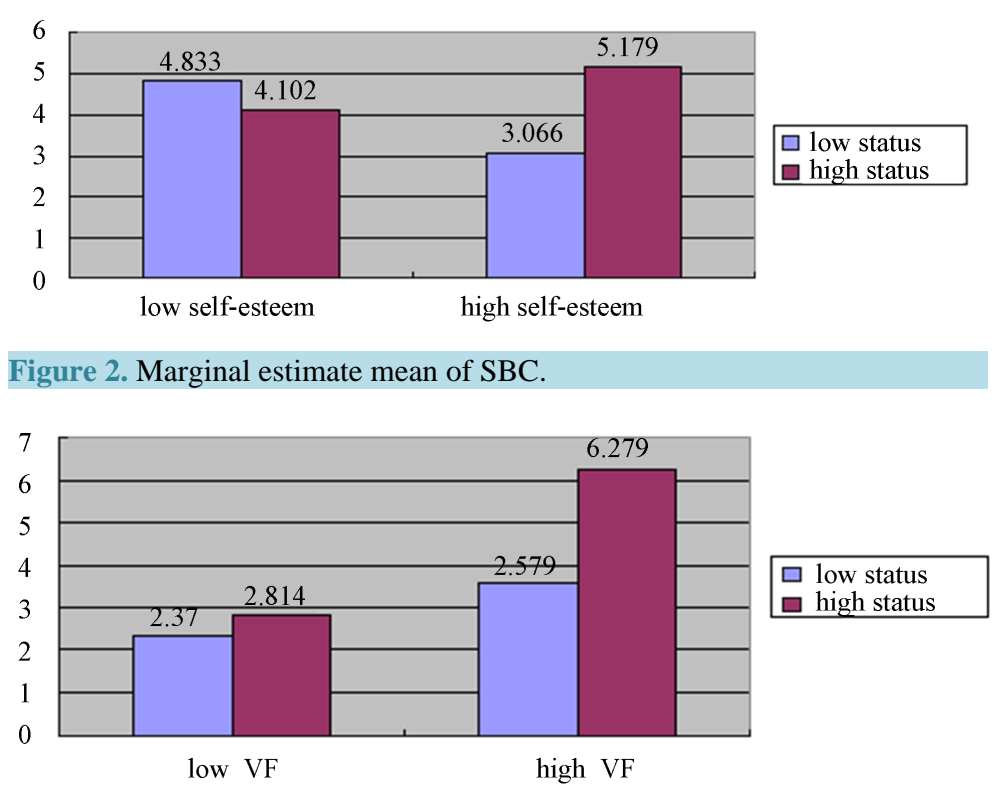

Figure 3. Marginal estimate mean of SBC.

3) Vanity has a regulating effect on above-mentioned relationship, too. Consumers, social status has no significant effect on their self-brand connection with luxury brands when they are in low vanity, while to highly peacockish consumers, the self-brand connection with luxury brands of those with low status is significantly lower than that of high status.

Vanity is something like showing off, which is contrary to the introverted, unassuming, moderate social values of Chinese nation and the traditional virtue of thrift. Chinese don't agree with the behavior of buying luxuries to flaunt one's status because of the moderate character which is rooted deeply in the minds of Chinese people. Here again proves that "behavior should match one's status" in China. Combining with the conclusion of 2), we can find it's self-esteem that actually urges consumers with low status to buy luxury brands, rather than vanity.

Finally, we have to say that, income could reflect social status to some extent, but by no means could it be the only criteria of status. We adopt income as the only criteria of classification of status in this research because of some reasons, so it's the main limitation of this study. In the future, we will use more scientific methods and criteria to measure status in order to further support our conclusions.

\section{Theoretical Implications}

According to the research findings, we can get the following theoretical marketing implications:

1) Implement the brand marketing strategy of cultural guidance. Luxury companies ought to have an in-depth comprehending about Chinese cultural traditions, histories, customs, social values, and so on, before doing business. To those companies who have already commenced operations, they should review, if necessary, modify their strategies and marketing model combining with Chinese unique culture in order to comply with the special consumption demands of Chinese consumers. It's very important and necessary for them to pay special attention to the differences of luxury consumption concepts, motivations and purposes between eastern and western consumers.

2) The results of this study show that Chinese consumers of low status are more rational than western ones in buying luxuries. Therefore, luxury companies should select the consumers with high income as target consumers. All the aspects, such as site selection, store decoration, product design and pricing, service, brand positioning, advertising, brand image building, brand culture construction, etc., should match up with the identity, wealth condition, power, achievement, image and temperament of the consumers with high status. The brand appeal and public visual identity of luxury must show a symbolic meaning of wealth and achievement (Wong and Ahuvia, 1998), and this could attract consumers to establish a strong and stable SBC. 
3) Self-esteem has a significantly positive regulating effect on SBC between luxury brands and consumers, especially it's self-esteem that actually urges consumers with lower status to buy luxury brands, rather than vanity. Therefore, it's better to transfer consumers' values of maintaining and improving the self-esteem and face that luxury brands can bring to them during the marketing dissemination.

4) Vanity has a regulating effect on the SBC between luxury brands and consumers, too. However, considering the somewhat derogatory meaning of vanity in Chinese culture, which runs counter to the traditional values of Chinese nation and is not accepted by Chinese people, it's better to avoid passing brand information with meaning of vanity, so as not to disgust consumers during the marketing process.

\section{References}

[1] Escalas, J.E. and Bettman, J.R. (2003) You Are What They Eat: The Influence of Reference Groups on Consumers' Connections to Brands. Journal of Consumer Psychology, 13, 339-348. http://dx.doi.org/10.1207/S15327663JCP1303_14

[2] Swaminathan, V., Page, K.L. and Gürhan-Canli, Z. (2007) “My” Brand or “Our” Brand: The Effects of Brand Relationship Dimensions and Self-Construal on Brand Evaluations. Journal of Consumer Research, 34, 248-259. http://dx.doi.org/10.1086/518539

[3] Carroll, B.A. and Ahuvia, A.C. (2006) Some Antecedents and Outcomes of Brand Love. Marketing Letters, 17, 79-89. http://dx.doi.org/10.1007/s11002-006-4219-2

[4] Moore, D.J. and Homer, P.M. (2008) Self-Brand Connections: The Role of Attitude Strength and Autobiographical Memory Primes. Journal of Business Research, 61, 707-714. http://dx.doi.org/10.1016/j.jbusres.2007.09.002

[5] Zhang, M.X. (2005) Confucian Cultural Values Interpretation of Symbolic Purchase Behavior-Concept Definition, Measurement, Modeling, and Marketing Strategy Proposal. Chinese Industrial Economy, 3, 106-112.

[6] Weiss, Y. and Fershtman, C. (1998) Social Status and Economic Performance: A Survey. European Economic Review, 42, 801-820. http://dx.doi.org/10.1016/S0014-2921(97)00137-2

[7] Dreze, X. and Nunes, J. (2009) Feeling Superior: The Impact of Loyalty Program Structure on Consumer's Perception of Status. Journal of Consumer Research, 35, 890-905. http://dx.doi.org/10.1086/593946

[8] O’Cass, A. and McEwen, H. (2004) Exploring Consumer Status and Conspicuous Consumption. Journal of Consumer Behaviour, 4, 25-39. http://dx.doi.org/10.1002/cb.155

[9] Wang, X., Cai, W., Sun, J.Q., Wu, S., Feng, Z.Q. and Jin, S.H. (2014) The Development and Comparison of Power: From the Perspective of Social Psychology Theory. Advances in Psychological Science, 22, 139-149.

[10] Sun, C.C. (2008) Symbol Consumption and Identity Ethics. Morality and Civilization, 1, 7-10.

[11] Rucker, D.D., Galinsky, A.D. and Dubois, D. (2012) Power and Consumer Behavior: How Power Shapes Who and What Consumers Value. Journal of Consumer Psychology, 22, 352-368. http://dx.doi.org/10.1016/j.jcps.2011.06.001

[12] Coopersmith, S. (1982) The Antecedents of Self-Esteem. The Journal of Humanistic Education and Development, 21, 18-21. http://dx.doi.org/10.1002/j.2164-4683.1982.tb00207.x

[13] Rudich, E.A. and Gregg, A.P. (2007) Self-Esteem Moderates Preferences for Accepting Versus Rejecting Interaction Partners. European Journal of Social Psychology, 37, 955-967. http://dx.doi.org/10.1002/ejsp.408

[14] White, K., Argo, J.J. and Sengupta, J. (2012) Dissociative versus Associative Responses to Social Identity Threat: The Role of Consumer Self-Construal. Journal of Consumer Research, 39, 704-719. http://dx.doi.org/10.1086/664977

[15] Zhang, W.L. (2004) Study of Taiwan College Students about Characteristics of Vanity, Materialism and the Relationship between Price Perception. Journal of Management, 21, 629-651.

[16] Yuan, S.F., Gao, Y. and Zheng, Y.X. (2009) Face Consciousness, Position Consumption Propensity and Conspicuous Consumption Behavior-Theoretical Model and Empirical Test. Collected Essays on Finance and Economics, 5, 81-86.

[17] Schiffman, L.G., Hansen, H. and Kanuk, L. (2011) Consumer Behavior: A European Outlook. Financial Times Prentice Hall, New York.

[18] Johar, J.S. and Sirgy, M.J. (1991) Value-Expressive versus Utilitarian Advertising Appeals: When and Why to Use Which Appeal. Journal of Advertising, 20, 23-33. http://dx.doi.org/10.1080/00913367.1991.10673345

[19] Davidson, N.M. (2009) Property and Relative Status. Michigan Law Review, 107, 757-817.

[20] Rosenberg, M. (1972) Society and the Adolescent Self-Image. 3rd Edition, Princeton University Press, Princeton.

[21] Netemeyer, R.G., Burton, S. and Lichtenstein, D.R. (1995) Trait Aspects of Vanity: Measurement and Relevance to Consumer Behavior. Journal of Consumer Research, 21, 612-626. http://dx.doi.org/10.1086/209422 
Scientific Research Publishing (SCIRP) is one of the largest Open Access journal publishers. It is currently publishing more than 200 open access, online, peer-reviewed journals covering a wide range of academic disciplines. SCIRP serves the worldwide academic communities and contributes to the progress and application of science with its publication.

Other selected journals from SCIRP are listed as below. Submit your manuscript to us via either submit@scirp.org or Online Submission Portal.
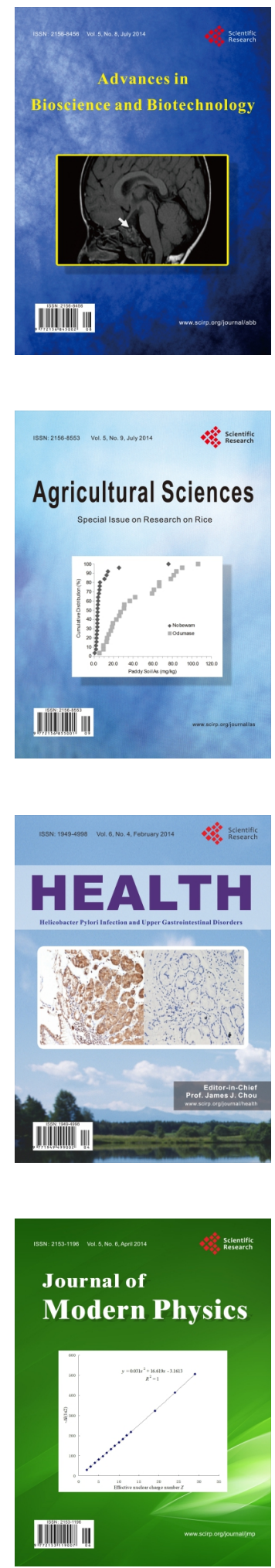
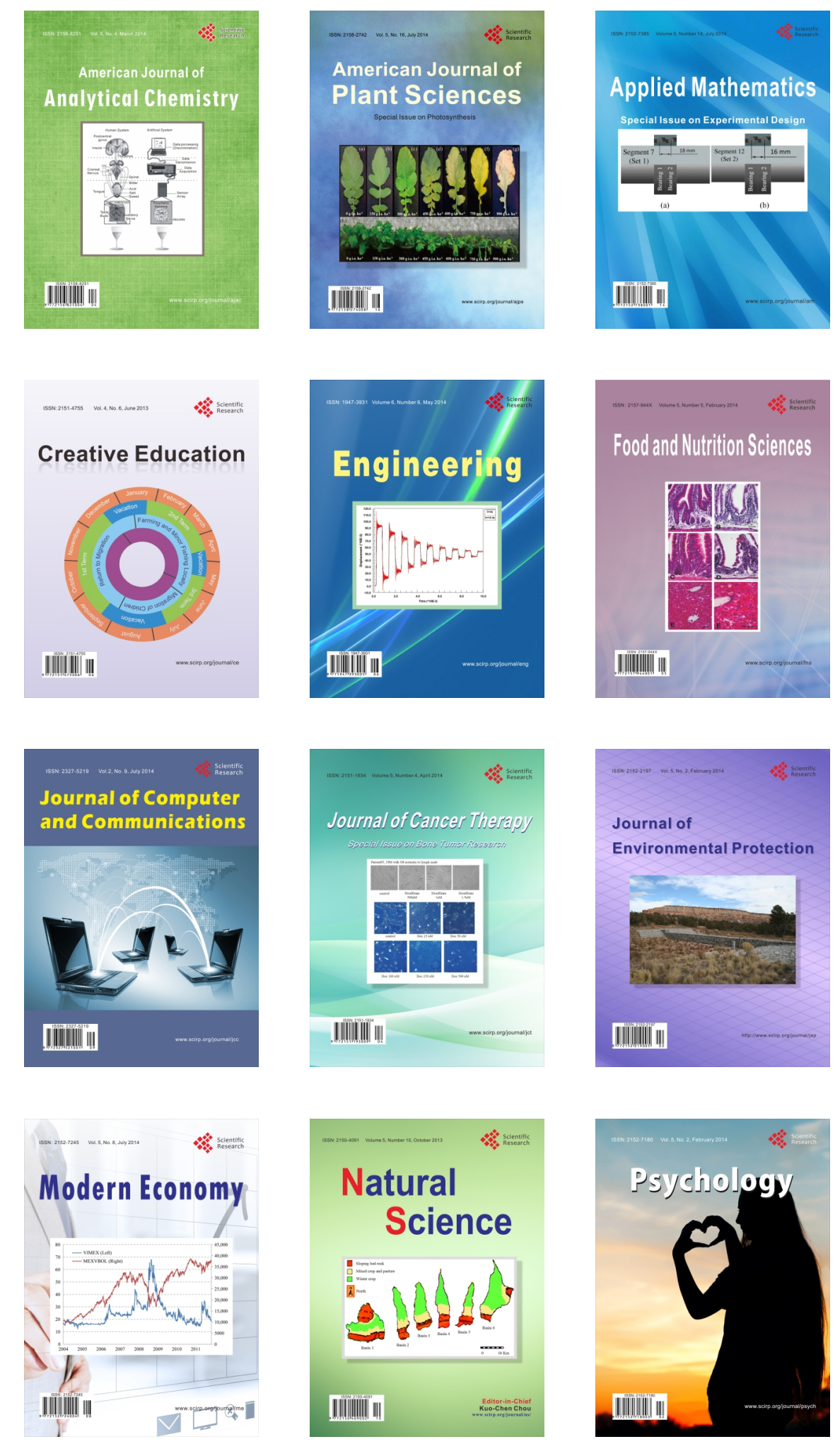